\title{
A PROSPECTIVE, CONTROLLED STUDY OF A 9/0 ELASTIC POLYPROPYLENE SUTURE FOR CATARACT SURGERY: REFRACTIVE RESULTS AND COMPLICATIONS
}

\author{
A. M. O'DRISCOLL ${ }^{1}$, R. R. GOBLE', G. N. HALLACK ${ }^{2}$ and N. C. ANDREW \\ Canterbury
}

\begin{abstract}
SUMMARY
A prospective, randomised study was performed on 52 patients undergoing routine limbal extracapsular cataract surgery to compare the effect of $10 / 0$ nylon and $9 / 0$ elastic polypropylene sutures on post-operative astigmatism. Both the magnitude and the axis of the astigmatism were measured by keratometry and refraction pre-operatively and at regular intervals for 3 months post-operatively. Both groups showed an increase in the magnitude of astigmatism immediately post-operatively. The polypropylene group showed a more rapid decrease in astigmatism over the first 7 days and subsequent stabilisation, although the only significant $(p<0.05)$ difference in astigmatism between the two groups was at 1 week postoperatively. Both groups showed 'with-the-rule' astigmatism immediately post-operatively, although more of the polypropylene group developed 'against-the-rule' astigmatism by the end of the study. Despite an early reduction in post-operative astigmatism in the polypropylene group, early spectacle prescribing would not be recommended because of the shift in the axis of astigmatism. In addition, the polypropylene group had a 4 times greater incidence of iris prolapse compared with the nylon group.
\end{abstract}

Ninety-two per cent of ophthalmic surgeons in the United Kingdom use a 'conventional' extracapsular technique for cataract surgery. ${ }^{1}$ Visual results of cataract surgery may be compromised by post-operative astigmatism. ${ }^{2}$ There are several factors related to both the incision and the sutures which produce this astigmatism. ${ }^{3}$ Suture tension is one of the most important factors as overtight sutures induce 'with-the-rule' astigmatism. ${ }^{4.5}$ Removal of the offending suture(s) in the early post-operative period can be undertaken in an attempt to reverse this trend although this practice delays the prescribing of any new spectacles. ${ }^{6}$

From: 'Department of Ophthalmology, Kent and Canterbury Hospital, Canterbury, Kent; ${ }^{2}$ Deknatel Inc., Fall River, Massachusetts, USA.

Correspondence to: Mr A. M. O’Driscoll, Birmingham and Midland Eye Hospital, Church Street, Birmingham B3 2NS, UK

Eye (1994) 8, 538-542 C 1994 Royal College of Ophthalmologists
Most surgeons use relatively inelastic, monofilament, high tensile strength sutures such as nylon. A suture which stretches if put under high tension will reduce overtightening and should induce a smaller degree of "with-therule' astigmatism. The $9 / 0$ polypropylene suture (Opthamend) in this study is a non-hydrolysable, monofilament suture which has just such elastic properties. We undertook a randomised, controlled, prospective study to assess the effect of this elastic suture on post-operative astigmatism and visual recovery. Our main aim was to discover whether refraction stabilised earlier after surgery.

\section{PATIENTS AND METHODS}

Fifty-two patients due to undergo routine extracapsular cataract surgery via a limbal section were recruited to participate in the study. Patients listed for corneal sections or phacoemulsification and those with coexisting anterior segment pathology were excluded. Patients were allocated to either the polypropylene group or the nylon group by a simple randomisation method, the surgeon knowing the type of suture only at the time of wound closure. The polypropylene group had 25 patients and the nylon group 27. The average age of the two groups was 77.6 years $(\mathrm{SD} \pm 12.9$ years) and 80.9 years $(\mathrm{SD} \pm 10.9$ years) respectively.

\section{Clinical Assessment}

Refractive status was assessed using retinoscopy and a standard set of trial lenses. Astigmatism was also objectively measured by keratometry with a Haag-Streit Javal Schiotz keratometer. All assessments were made by one observer (A.M.O'D.). The readings were taken the day before surgery and 1 day, 1 week, 1 month and 3 months post-operatively. Unaided and best corrected Snellen visual acuity were recorded. Full slit-lamp biomicroscopy was also undertaken at each visit and in particular the presence of giant papillary conjuctivitis (GPC) from protruding sutures, iris prolapse and wound leakage was noted. 
Table I. Post-operative complications of the 52 patients recruited

\begin{tabular}{lcc}
\hline & $\begin{array}{c}\text { Nylon } \\
(n=27)\end{array}$ & $\begin{array}{c}\text { Polypropylene } \\
(n=25)\end{array}$ \\
\hline Iris prolapse & $1^{\mathrm{a}}$ & $4^{\mathrm{a}}$ \\
Wound leak & 0 & 2 \\
Protruding sutures & 0 & 7 \\
Corneal ulcer & 0 & $1^{\mathrm{a}}$ \\
Pupil-block glaucoma & $1^{\mathrm{a}}$ & 0 \\
Defaulted from study & $1^{\mathrm{a}}$ & 0 \\
\hline
\end{tabular}

apatients excluded from study.

\section{Operative Technique}

The senior surgeon was responsible for the majority of the surgery, with $16 \%$ of the polypropylene group (4 of 25 ) and $19 \%$ of the nylon group ( 5 of 27 ) being performed by juniors under his supervision. All patients had a superiorly placed limbal incision with a diamond knife after conjunctival peritomy. The length of the section was recorded. An extracapsular technique was used with a 'can opener' capsulotomy, nucleus expression and manual irrigation/ aspiration of residual soft lens matter. All patients received Kabi Pharmacia 724:B posterior chamber implants. The limbal section was sutured with either the elastic 9/0 polypropylene (Opthamend O-8046) suture or 10/0 nylon (Alcon:208101) suture. Five interrupted sutures were inserted using a three:one:one knot configuration. The nylon knots were buried by rotation.
Attempted burial of the polypropylene resulted in exaggerated stretching. The polypropylene knots were therefore turned to the scleral side of the wound and left under the conjunctiva, similar to the technique used with a silk suture. A subconjunctival injection of $125 \mathrm{mg}$ cefuroxime was given at the end of surgery and the eye was covered with a plastic eye shield. Patients in whom the above protocol was not adhered to, as well as those whose eye required further surgery during the study period, were excluded from the study.

Dexamethasone/neomycin/polymyxin B (Maxitrol, Alcon) eyedrops were prescribed after surgery, initially four times each day. These were gradually reduced and stopped by 8 weeks post-operatively.

\section{RESULTS}

\section{Complications and Exclusions}

Three of the 27 patients recruited to the nylon group and 5 of the 25 recruited to the polypropylene group were excluded. Table I lists the post-operative complications of the patients recruited to the study. Four patients in the polypropylene group $(16 \%)$ and 1 patient in the nylon group $(4 \%)$ were excluded due to iris prolapse as this necessitated surgical repair. These incidences of iris prolapse in the two groups did not reach statistical significance $(p=0.24)$ using Fisher's exact test. ${ }^{7}$ Two $(8 \%)$ of the

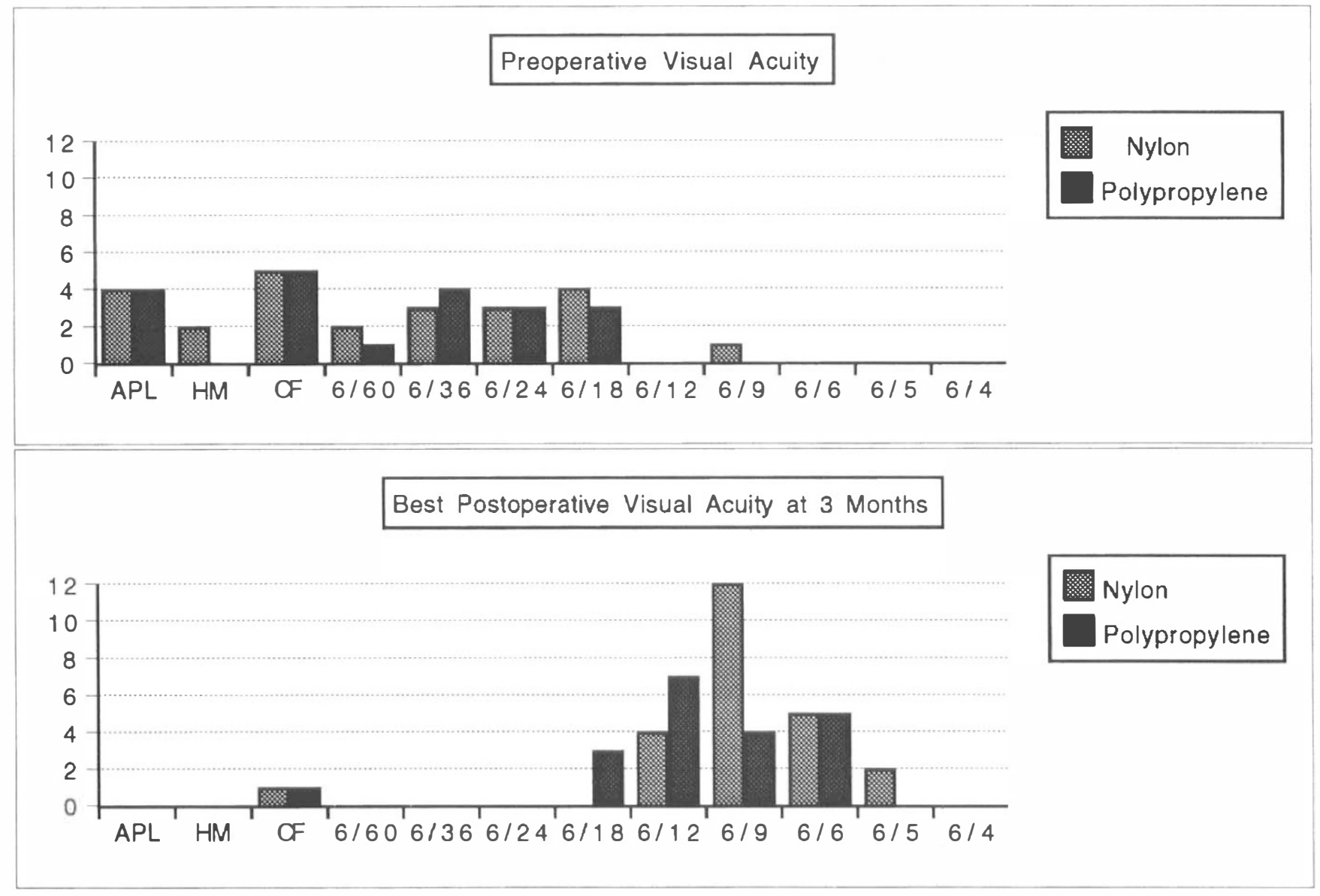

Fig. 1. Pre-operative and 3 month post-operative visual acuities in patients undergoing cataract surgery with either $10 / 0$ nylon or $9 / 0$ polypropylene sutures. 
Pre-operative

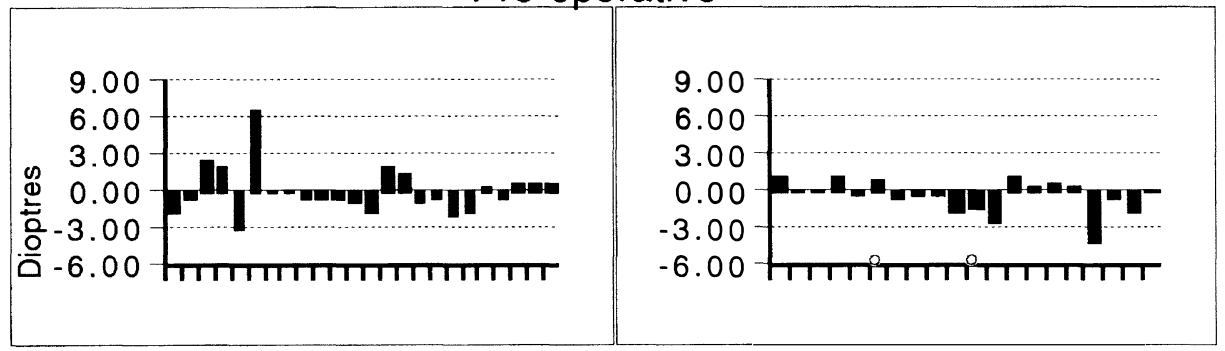

\section{Day 1}

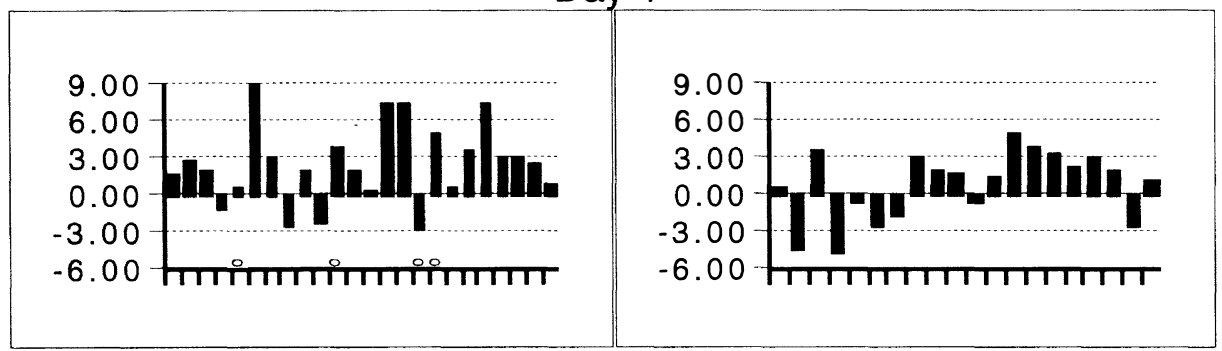

Week 1

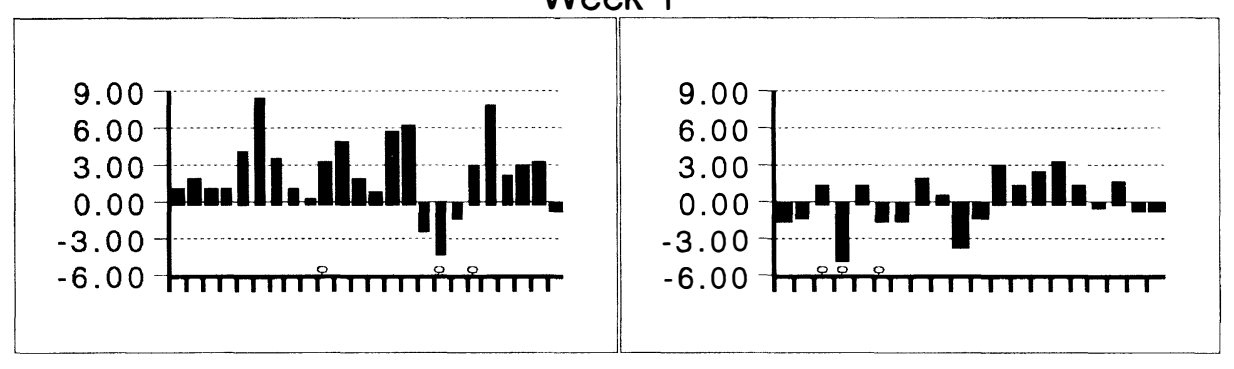

Month 1

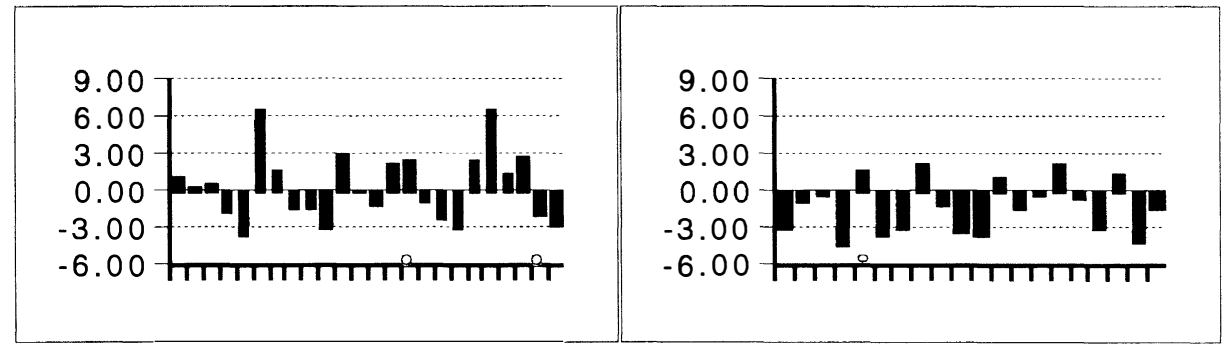

Month 3

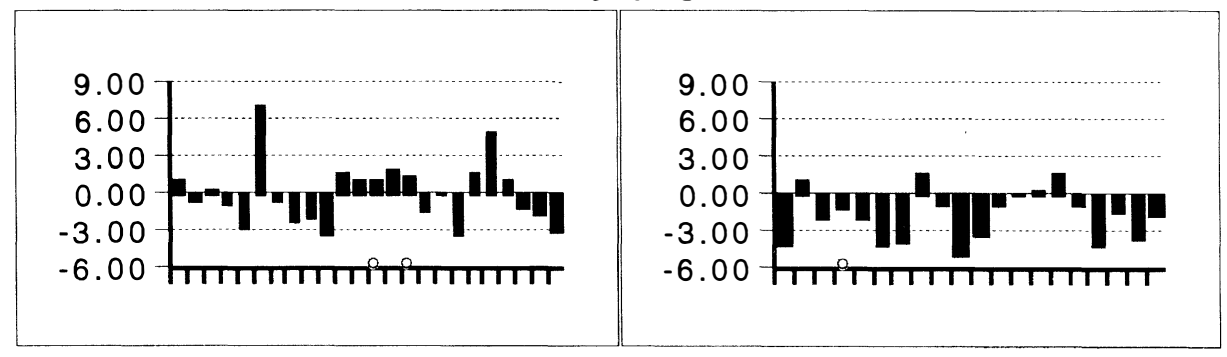

Fig. 2. Pre-operative and post-operative astigmatism in the nylon and polypropylene groups. The magnitude of astigmatism is given in dioptres on the y-axis. 'With-the-rule' astigmatism is represented by a positive value and 'against-the-rule' as a negative value. Oblique astigmatism is show'n with the letter ' $O$ ' and plotted as either positive $\left(45^{\circ}-55^{\circ}\right.$ and $\left.120^{\circ}-130^{\circ}\right)$ or negative $\left(35^{\circ}-45^{\circ}\right.$ and $\left.135^{\circ}-145^{\circ}\right)$. Each column represents an individual patient. 
Table II. A comparison of the average keratometric astigmatism (in dioptres) of the polypropylene and nylon groups

\begin{tabular}{|c|c|c|c|c|c|}
\hline & \multirow[b]{2}{*}{ Pre-operative } & \multicolumn{4}{|c|}{ Post-operative } \\
\hline & & 1 day & 1 week & 1 month & 3 months \\
\hline Nylon & $1.3( \pm 1.4)$ & $3.2( \pm 2.4)$ & $2.7^{a}( \pm 2.3)$ & $2.2( \pm 1.6)$ & $1.9( \pm 1.6)$ \\
\hline Polypropylene & $0.9( \pm 1.0)$ & $2.5( \pm 1.4)$ & $1.7^{\mathrm{a}}( \pm 1.2)$ & $2.1( \pm 1.3)$ & $2.1( \pm 1.5)$ \\
\hline
\end{tabular}

${ }^{\mathrm{a}} p<0.05$ (Student's $t$-test).

polypropylene group were noted to have leaking wounds 1 week post-operatively. Both settled with conservative treatment and are included in the polypropylene group. Thirty-five per cent ( 7 of 20) of the polypropylene group had sutures protruding through the conjunctiva although only 1 patient was symptomatic with GPC. The protruding sutures were removed at the 3 month follow-up visit. No such problems arose in the nylon group as the knots were buried. The patient who developed herpetic stromal keratitis settled on topical acyclovir treatment, but was left with profound corneal scarring which precluded accurate retinoscopy or keratometric assessment. The patient with pupil-block glaucoma had the surgical incision partly reopened and a surgical peripheral iridectomy performed because laser iridotomy was technically impossible due to a combination of corneal oedema, a flat anterior chamber and a deeply pigmented iris.

\section{Visual Acuity}

Fig. 1 shows the pre-operative and best post-operative visual acuities in both groups. One patient with severe atrophic age-related macular degeneration and another with dense amblyopia had final visual acuities of only counting fingers (CF). There was no significant difference between the two groups in terms of average visual acuity.

\section{Astigmatism}

A high degree of correlation between keratometry and refraction for assessing astigmatism has been demonstrated. ${ }^{6,8}$ We have used objective keratometric results in assessing both the magnitude and the axis of astigmatism. The results of the average magnitude of astigmatism are shown in Table II. The difference between the two groups pre-operatively is not significant $(p>0.1)$ using an unpaired Student's $t$-test. The magnitude of post-operative astigmatism appeared to reduce gradually in the nylon group, compared with the rapid reduction in the polypropylene group over the first 7 days. The only statistically significant $(p<0.05)$ difference between the two groups was seen at 1 week post-operatively.

For the purposes of this study we have further divided our patients into three subgroups according to the axis of astigmatism. If the higher keratometric reading was within $30^{\circ}$ of the vertical meridian then the patient was said to have 'with-the-rule' astigmatism, those within $30^{\circ}$ of the horizontal meridian were 'against-the-rule' and the rest were 'oblique'. The results are given in Fig. 2.

Wound length is a factor in the aetiology of surgically induced astigmatism, and the average wound lengths were $10.7 \mathrm{~mm}(\mathrm{SD} \pm 1.3 \mathrm{~mm})$ in the polypropylene group and $10.6 \mathrm{~mm}(\mathrm{SD} \pm 1.1 \mathrm{~mm})$ in the nylon group.

\section{DISCUSSION}

The factors which influence astigmatism following cataract surgery are related to the incision itself and the method of suturing. ${ }^{3.9}$ There was no significant difference in the average lengths of the surgical incisions of the two groups. The incisions were closed using five interrupted sutures which were tied using the same technique. Both suture materials initially induced post-operative astigmatism which was then observed to reduce with time.

There was a gradual decrease in the average magnitude of astigmatism in the nylon group over the 3 month study period, with the biggest decrease occurring between 1 week and 1 month post-operatively. The polypropylene suture initially induced a lower magnitude of astigmatism which decreased rapidly over the first 7 days to reach a stable value. When the axis of astigmatism was taken into account in this latter group, it was noted that there was a progressive increase in the number of patients with 'against-the-rule' astigmatism. The polypropylene group initially induced less 'with-the-rule' astigmatism implying that the elastic sutures were not as tight as the nylon. The elastic suture may have continued to stretch and produced a progressive shift 'against-the-rule', with only $16 \%$ of the patients showing any 'with-the-rule' astigmatism at 3 months.

'Against-the-rule' astigmatism is much less amenable to treatment by simple suture removal and is therefore a considerable management problem. ${ }^{5}$ The shift of axis in the polypropylene suture group means that despite the average magnitude of astigmatism remaining relatively stable from about 1 week, earlier prescribing of a postoperative refractive correction is not possible. A study comparing $9 / 0$ and $10 / 0$ nylon with $10 / 0$ polypropylene demonstrated that the polypropylene took an average of 12 months to reach a stable refraction compared with between 1 and 4 months for the nylon. ${ }^{9}$

Hydrolysis of nylon sutures produces a late astigmatism shift 'against-the-rule' which continues at least 2 years post-operatively. ${ }^{9}$ Polypropylene is non-hydrolysable and does not show this late shift. When nylon hydrolyses, clinical problems such as infective keratitis or GPC may also occur. ${ }^{10.11}$ The problems of protruding polypropylene sutures and GPC were a result of the knots not being buried in the wound. Tying the knot in a buried position should eliminate this problem.

The $16 \%$ incidence of iris prolapse in the polypropylene group was unacceptably high despite not reaching statistical significance when compared with the nylon group. The single case in the nylon group was operated on by a junior member of staff and, taking this factor into account, 
the $4 \%$ incidence was probably not excessively high. ${ }^{12}$ The post-operative elasticity of the polypropylene suture may be partly responsible for the poor wound security. Further modification of the suturing technique in terms of a more interrupted or even a continuous suture may eliminate this problem and has been recommended. ${ }^{9}$ Modification of surgical technique was needed when using the polypropylene suture as undue tension placed on it when attempting to pull the tissues together produced stretching of the suture. The suture material may have been weakened and this could be partially responsible for the high incidence of iris prolapse.

In conclusion, the elastic polypropylene suture appeared to induce less 'with-the-rule' astigmatism in the early post-operative period by reducing inadvertent overtightening. However, the prescription of new spectacles could not be undertaken as a shift towards 'against-therule' astigmatism continued for up to 3 months after surgery. This was thought to be due to increasing wound laxity. A significantly higher incidence of iris prolapse was an additional worrying factor. It may be that the use of an alternative suturing technique will prevent these problems. Further studies will need to be undertaken to show whether this suture has many advantages over nylon.

Mr A. M. O’Driscoll, Mr R. R. Goble and Mr N. C. Andrew have no proprietary interest in the Opthamend suture.
Key words: Astigmatism, Cataract surgery. Polypropylene suture.

\section{REFERENCES}

1. Courtney P. The National Cataract Surgery Survey. I. Method and descriptive features. Eye 1992;6:487-93.

2. Thornton SP. Cataracts and the surgical control of astigmatism. J Cataract Refract Surg 1989;15:11.

3. Van Rij G, Waring GO. Changes in corneal curvature induced by sutures and incisions. Am J Ophthalmol 1984; 98:773-83

4. Jaffe NS, Clayman HM. The pathophysiology of corneal astigmatism after cataract extraction. Ophthalmology 1975 79:615-30

5. Wishart MS, Wishart PK, Gregor ZJ. Corneal astigmatism following cataract extraction. Br J Ophthalmol 1986;70: $825-30$

6. Stanford MR, Fenech T, Hunter PA. Timing of removal of sutures in control of post-operative astigmatism. Eye 1993; 7:143-7.

7. Campbell MJ, Machin D. Medical statistics: a commonsense approach. Chichester: Wiley, 1990:136-7.

8. Misson GP. Keratometry and post-operative astigmatism. Eye 1992;6:63-5.

9. Cravey TV. Long-term corneal astigmatism related to selective elastic, monofilament, nonabsorbable sutures. J Cataract Refract Surg 1989;15: 61-9.

10. Acheson JF, Lyons CJ. Ocular morbidity due to monofilament nylon corneal sutures. Eye 1991;5:106-12.

11. Jackson H, Bosanquet R. Should nylon corneal sutures be routinely removed? Br J Ophthalmol 1991;71:663-4.

12. Naylor G. Iris prolapse: who? when? why? Eye 1993;7: 465-7. 